MICE-NOTE-DET-96

\title{
Commissioning Report
}

\author{
for the M.I.C.E.
}

2 slot VLPC Cryocooler Cryostat

D-ZERO ENGINEERING NOTE \# 3823.000-EN-578

May 6, 2005

Author: Russell A. Rucinski

$\mathrm{PPD} / \mathrm{MD} / \mathrm{D} 0$ Operations

Fermi National Accelerator Laboratory, Batavia, IL, U.S.A. 


\section{2 slot VLPC cryostat commissioning report}

Table 1. Summary of performance.

\begin{tabular}{|l|c|c|c|c|c|}
\hline Operating period & $\begin{array}{c}\# 1 \\
\text { March 30 }\end{array}$ & $\begin{array}{c}\# 2 \\
\text { April 11 }\end{array}$ & $\begin{array}{c}\# 3 \\
\text { April 22 }\end{array}$ & $\begin{array}{c}\# 4 \\
\text { April 28 }\end{array}$ & $\begin{array}{c}\text { Design } \\
\text { Values }\end{array}$ \\
\hline Stage 1 lowest & $55 \mathrm{~K}$ & $47 \mathrm{~K}$ & $41 \mathrm{~K}$ & $\mathbf{4 7 ~ K}$ & $\mathbf{4 5}$ Kelvin \\
\hline Stage 1 heat load & 50 Watts & 45 Watts & 38 Watts & $55 \mathrm{~W}$ & $\mathbf{5 0 ~ W a t t s}$ \\
\hline Stage 2 lowest & $14 \mathrm{~K}$ & $7.9 \mathrm{~K}$ & $7.2 \mathrm{~K}$ & $\mathbf{5 . 3 ~ K}$ & $\mathbf{5 . 5}$ Kelvin \\
\hline Stage 2 heat load & $22 \mathrm{Watts}$ & 10 Watts & 7 Watts & $\mathbf{3}$ to 4 W & 3 Watts \\
\hline Slot 1, Cass\#105 & $?$ & $20.7 \mathrm{~K}$ & $16.8 \mathrm{~K}$ & $7.5 \mathrm{~K}$ & $\mathbf{8 ~ K e l v i n}$ \\
\hline Slot 2, Cass\#111 & $?$ & $20 \mathrm{~K}$ & 23.7 & $7.1 \mathrm{~K}$ & $\mathbf{8}$ Kelvin \\
\hline
\end{tabular}

\section{Summary of Activity:}

March 25-Cryostat ready, partial cool down

March 28 thru 30 - Cooled and operated, realized heat load and temperatures too high.

April 1 thru April 6 - Warmed up, better radiation insulation added.

April 7 thru April 11 - Cooled and operated. Observed poor thermal connection to cassette. Heat loads too high.

April 12 thru April 19 - Warmed up, improved thermal connections, segmented G-10 to reduce conduction heat loads, added copper radiation shield, improved insulation.

April 20 thru April 22 - Cooled and operated. Observerd poor thermal connection to cassette.

April 22 thru April 27 - Warmed up, changed thermal connection to indium wire. April 28 thru May 6 (and continuing) -Successfully arrived at cryogenic design values!

Table 2. Design Heat load estimates and expected temperatures.

\begin{tabular}{|l|l|l|}
\hline & Stage $1(\sim 60 \mathrm{~K})$ & Stage $2(\sim 7 \mathrm{~K})$ \\
\hline Cassette & 7.7 watts & 0.82 watts \\
\hline Envelope & 15.0 watts & 0.45 watts \\
\hline Miscellaneous & 2 watts & 0.10 watts \\
\hline Total per slot & 25 watts & 1.4 watts \\
\hline Total for cryocooler & 50 watts & 2.8 watts \\
\hline
\end{tabular}




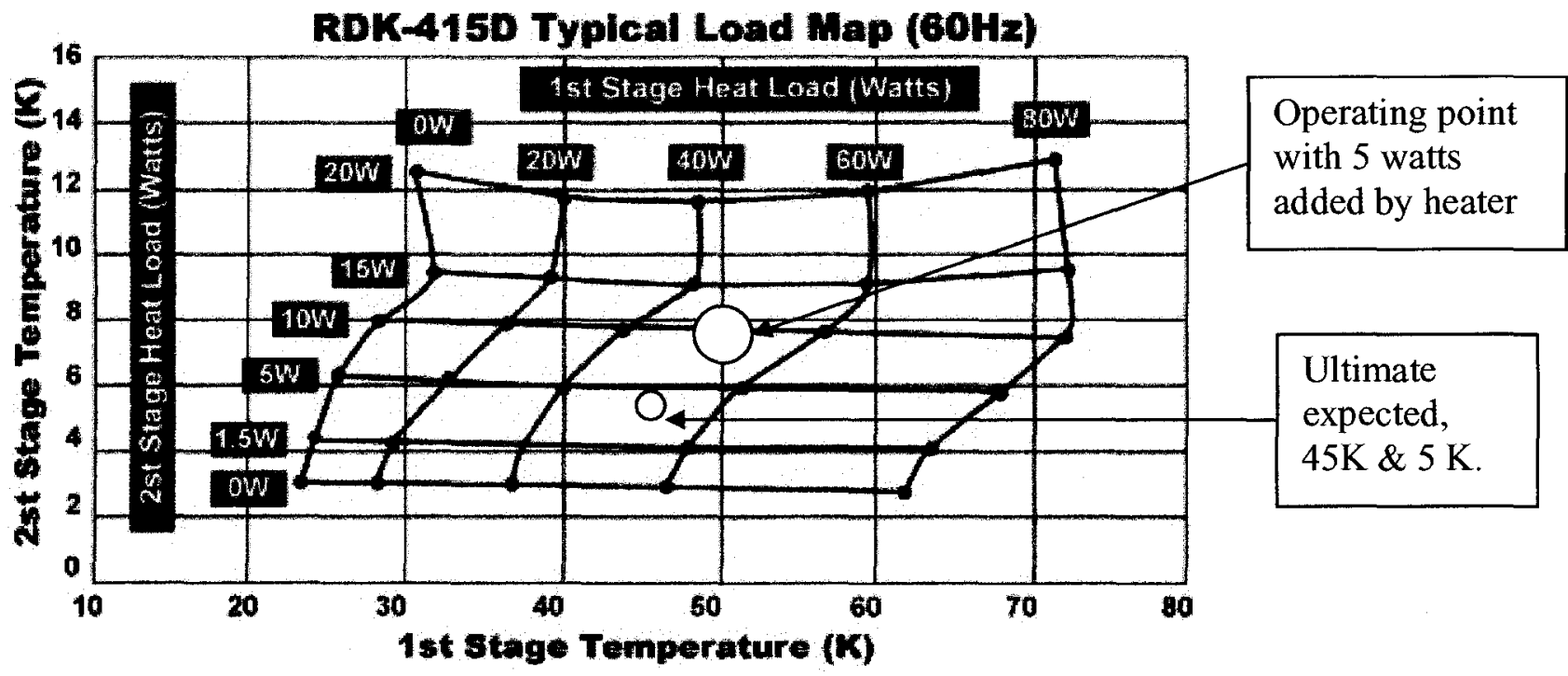

Figure 1. Refrigeration load map for the Sumitomo cryocooler. $60 \mathrm{~Hz}$ power.

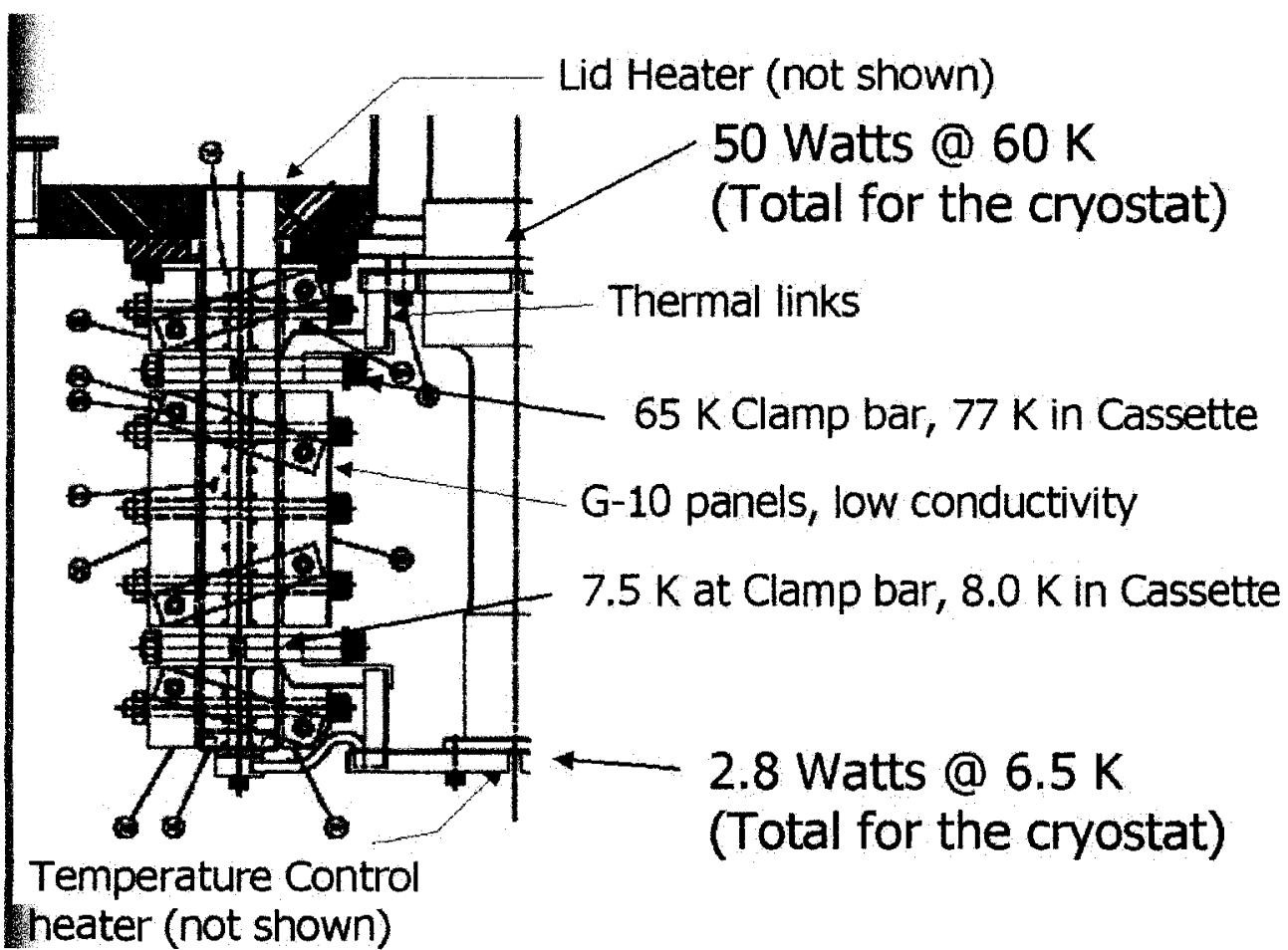

Figure 2. Sketch of thermal design. Early design numbers. 


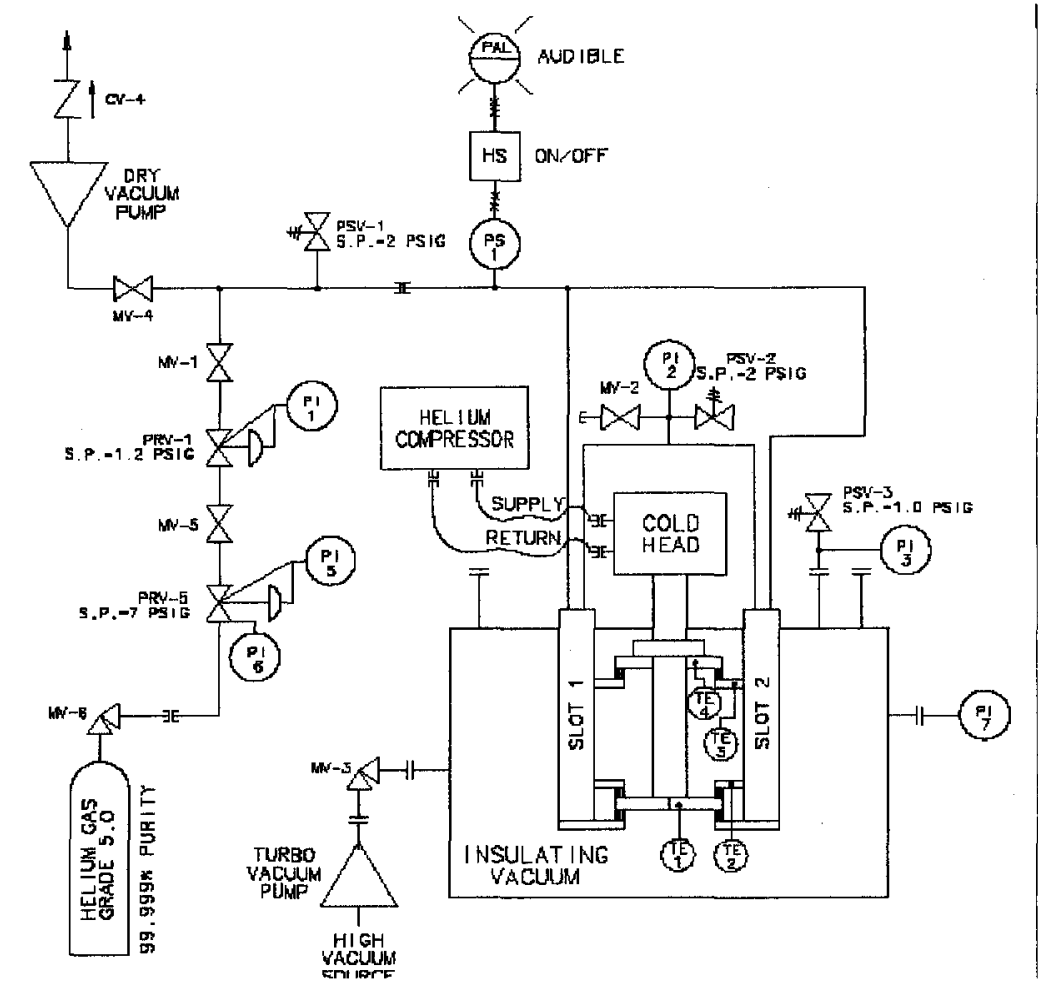

Figure 3. Flow schematic of cryogenic operating system

\section{Instrumentation:}

Sensor 1: Originally a $100 \mathrm{ohm}$ carbon resistor, Allen Bradley. FNAL calibration serial number 930917-A5. Useful temperature range is 4 to $78 \mathrm{Kelvin}$. Mounted on the screw attaching the stage 2 thermal link to the cold head. Changed to a Cernox CX-1050-AA, serial number X35784 for the April $5^{\text {th }}$ cool down.

Sensor 2: Originally a $100 \mathrm{ohm}$ carbon resistor, Allen Bradley. FNAL calibration serial number 930917-A6. Useful temperature range is 4 to 78 Kelvin. Mounted on the edge of the stage 2 thermal link on the cassette side of the flexible section. Resistor was changed out to serial number $920125-\mathrm{A} 2$ for the April $5^{\text {th }}$ cool down. Finally changed to a Cernox CX-1050-SD, serial number X38128 on April $26^{\text {th }}$.

Sensor 3: Silicon diode, Oxford part number PDZ0004, serial number 3445S. Useful temperature range is $4-300$ Kelvin range. Mounted on the edge of the stage 1 thermal link on the cassette side of the flexible section.

Sensor 4: $100 \mathrm{ohm}$ platinum sensor, Lakeshore PT-102. Useful temperature range 40 to 300 Kelvin. Mounted on the thermal link close to the stage 2 cold head for the April $5^{\text {th }}$ cool down. Moved to the stage 1 cryo cooler attachment location for the April 20 cool down.

Insulating vacuum: Hastings DV-6 thermocouple gage, useful range 1-1000 microns. Granville Phillips 275 convectron gage tube, useful range 1 millitorr - 1000 Torr.

Convectron changed to a MKS instruments Cold Cathode gage model 421. 
Time period $=14$ to 17 hours; Stage 1 temperature slowly increased and stabilized at 55 to 56 Kelvin for the duration. This type of behavior was observed during the April $7^{\text {th }}$ $12^{\text {th }}$ cool down and seems to correspond to a change in stage 2 cooling.

Time $=24$ hours; Two $100 \mathrm{ohm}$ Allen Bradley carbon resistors on stage 2 were read out using a digital voltmeter. Sensor 1 (cold head) was 17.0 Kelvin, Sensor 2 (thermal link at cassette) was 16.6 Kelvin.

On day 2 the calibration curves in the Oxford ITC503 controller were configured and we had an active temperature display.

Time $=38$ hours; Stage 2 reached minimum temperature. Sensor 1 on the cold head was 13.7 Kelvin. Sensor 2 on the thermal link was $14.9 \mathrm{~K}$. After this low point, the sensors rose in temperature probably due to changes in vacuum jacket pressure (see next paragraph).

Table 3. Coldest temperatures reach during inaugural cool down.

$\begin{array}{cccc}\begin{array}{c}\text { 3/29/2005 } \\ \text { Coldest Temps }\end{array} & \text { T1 } & \text { T2 } & \text { T3 } \\ 18: 20 & 14.89 & 15.345 & 54.37 \\ 19: 20 & 14.46 & 15.12 & 54.72 \\ 20: 20 & 14.1 & 14.958 & 54.93 \\ 21: 25 & 13.92 & 14.895 & 55.07 \\ 22: 21 & 13.78 & 14.893 & 55.17 \\ 23: 30 & 13.67 & 14.906 & 55.3\end{array}$

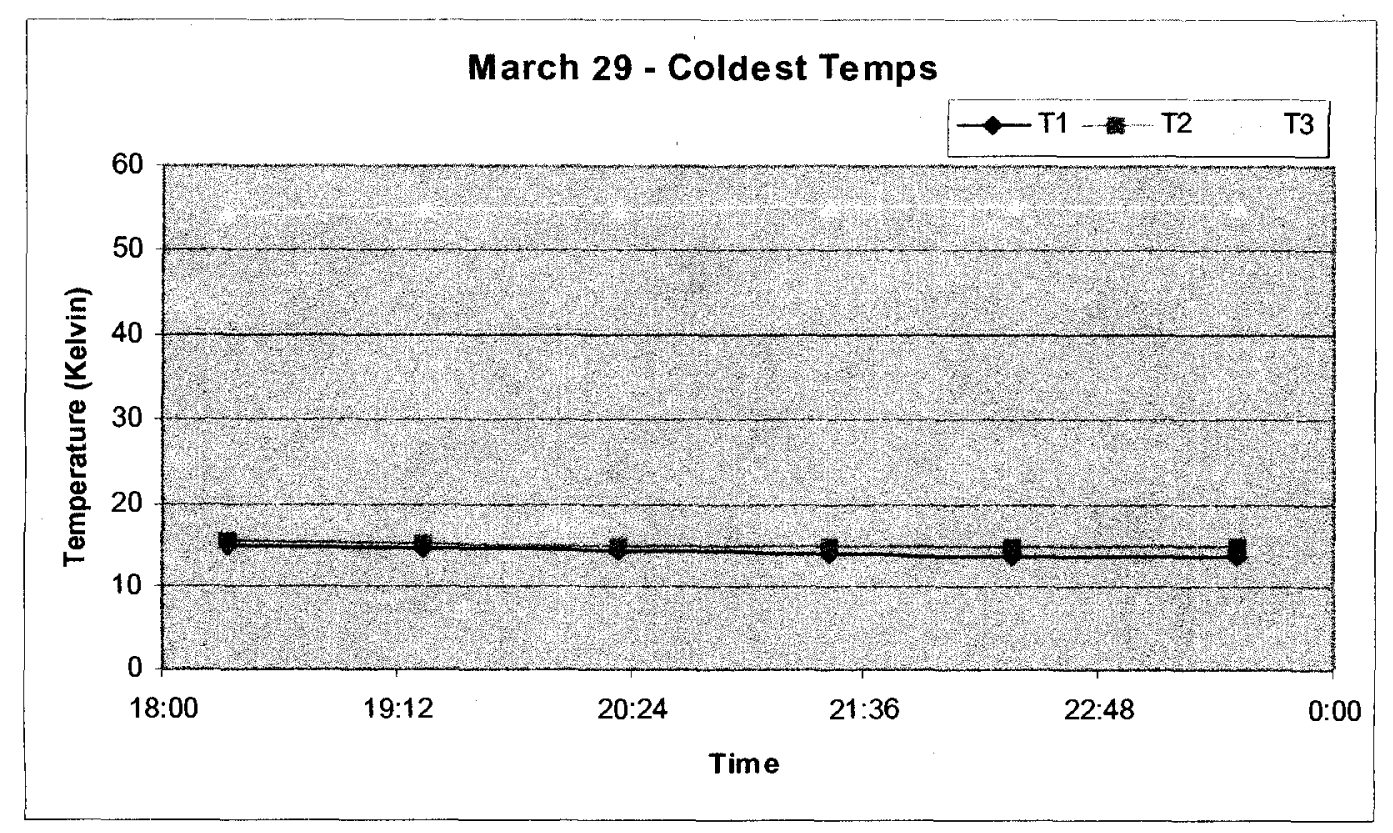

Figure 4. Coldest temperatures reach during inaugural cool down. 
On day 2 , it was observed that vacuum shell temperatures were $2 \mathrm{C}$ cooler on front $\&$ back corresponding to line of sight to components between the cassette slots. The vacuum jacket pressure was less than or equal to 1 micron as indicated by a Hastings DV6 thermocouple gage and Granville Phillips 275 convectron gage tube. The vacuum jacket was connected to a turbomolecular vacuum pump cart by a 6 meter pumping line during the cooling. Some experimentation of isolating the cryostat from the pumping cart. Initially after a few hours of having the vacuum jacket isolated temperatures dropped, but then they started rising. After 12 hours of being isolated the vacuum jacket pressure rose to 2 microns and the pumping cart was re-opened to the vacuum shell on day 3 . The temperatures on stage 2 also rose from their minimums on day 2 to steady state values of around 16 Kelvin on day 3.

Testing of the cold head heater was done by inputting 1, 2, 3, 4, and 5 Watts of heater power.

Table 4. Heater power test and temperatures, March 30, 2005

$\begin{array}{cccccc}\begin{array}{c}\text { 3/30/05 PM } \\ \text { Heater Power }\end{array} & \text { T1 } & \text { T2 } & \text { T3 } & \text { T1 Rise } & \text { T2 Rise } \\ 0 & 16.92 & 16.05 & 53.7 & 0 & 0 \\ 1 & 17.29 & 16.567 & 53.65 & 0.37 & 0.517 \\ 2 & 17.84 & 17.236 & 53.61 & 0.92 & 1.186 \\ 3 & 18.74 & 18.182 & 53.61 & 1.82 & 2.132 \\ 4 & 19.34 & 18.792 & 53.49 & 2.42 & 2.742 \\ 5 & 20.33 & 19.876 & 53.27 & 3.41 & 3.826\end{array}$

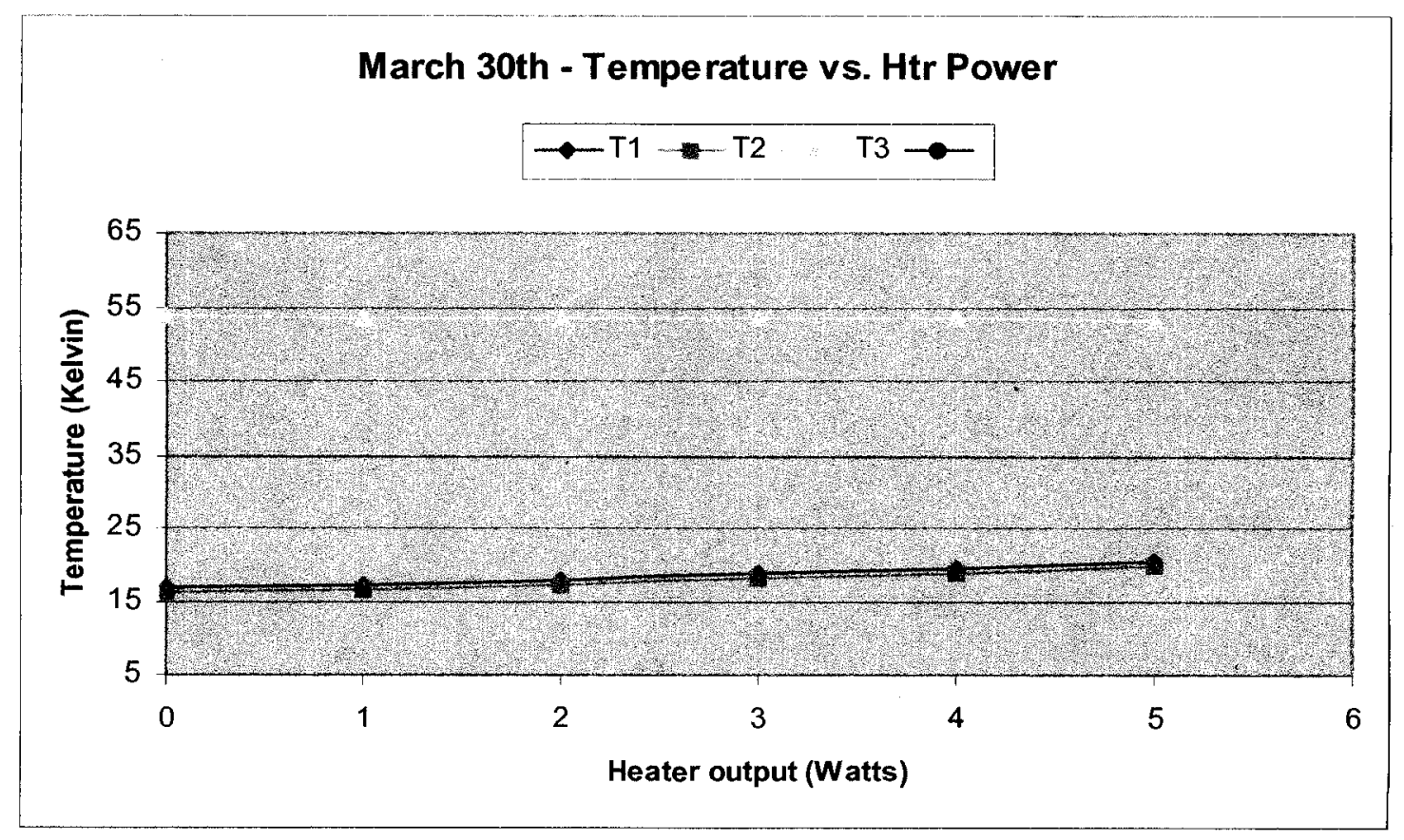

Figure 5. Heater power test and temperatures, March 30, 2005 
At the end of day 3, the cryo cooler was turned off and a warm up began.

Table 5. Warm up temperatures

$\begin{array}{cccc}\begin{array}{c}\text { 3/30/05 PM } \\ \text { Warm up }\end{array} & \text { T1 } & \text { T2 } & \text { T3 } \\ 17: 00 & 17.96 & 17.28 & 53.59 \\ 17: 15 & 39.1 & 40.1 & 80.6 \\ 17: 30 & 47 & 48.6 & 98.6 \\ 18: 00 & 54.1 & 55.5 & 117 \\ 18: 15 & 57.29 & 59.31 & 125.49 \\ 18: 30 & 60.79 & 63.35 & 132.55 \\ 18: 46 & 64.94 & 68.12 & 139.37 \\ 19: 01 & 69 & 72.77 & 145.05\end{array}$

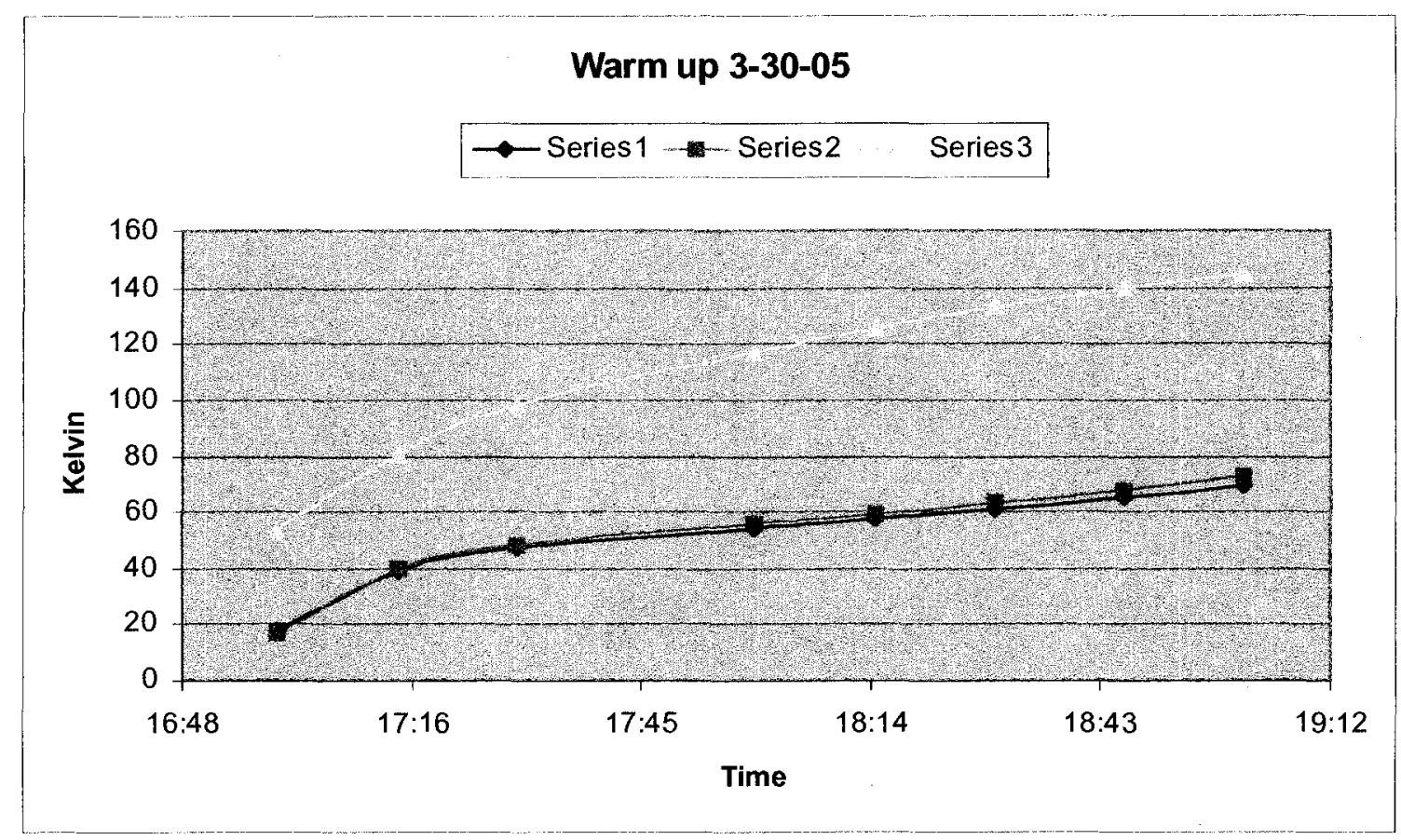

Figure 6. Warm up temperatures

Comments: The operating point of $55 \mathrm{~K}$ for stage 1 and $14 \mathrm{~K}$ for stage 2 corresponds to an estimated heat load of 50 Watts to stage 1 and 22 Watts for stage 2 . This estimation is inferred from the Sumitomo $60 \mathrm{~Hz}$ load map. Clearly the heat load was too high. The temperature depression of the vacuum jacket indicated the need to add radiation insulation in that area. I looked up the emissivity of the G-10 surface (plastic) and found that it was quite high, around 0.90 versus shiny metals which have an emissivity of 0.10 . Calculations showed that the radiation heat load could be 5 to 50 Watts for the surfaces below stage 1. A free convection heat transfer calculation for the vacuum jacket being an average of $294 \mathrm{~K}$ with an ambient temperature of $295.4 \mathrm{~K}$ indicated at least 2 Watts of 
heat transfer from cylindrical shell. The lid temperature was maintained at $289 \mathrm{~K}$ by a lid heater.

Modifications done April 4th and 5th: Low emissivity tape applied to all flat surfaces of the G-10 panels and exposed surfaces of the cold head and thermal links. Multi-layer insulation blankets added on top of stage 2 thermal link (20 layers) and covering the side and bottom area between the cassettes (15 layers). Already existing was a 24 layer blanket going that covered the outboard side of the cassette and bottom. Also existing was a layered blanket between the underside of the lid and the top of the stage 1 link. These rectangular shaped blankets created a box like surrounding of the assembly. An additional 3 layers were wrapped around the perimeter of the box, closing off the vertical seam joints. Clearances on all sides of the assembly were checked and confirmed to be at least 1/4" from the vacuum shell. A Leybold Turbovac $50 \mathrm{~L} / \mathrm{s}$ turbo molecular pump was mounted directly to the vacuum shell, greatly improving initial vacuum pressures.

A platinum temperature sensor was added to stage 2 to give room temperature to 50 Kelvin information during cool down. The original carbon resistor for sensor \#2 accidently had it' leads broken off. It was replaced with a similar sensor.

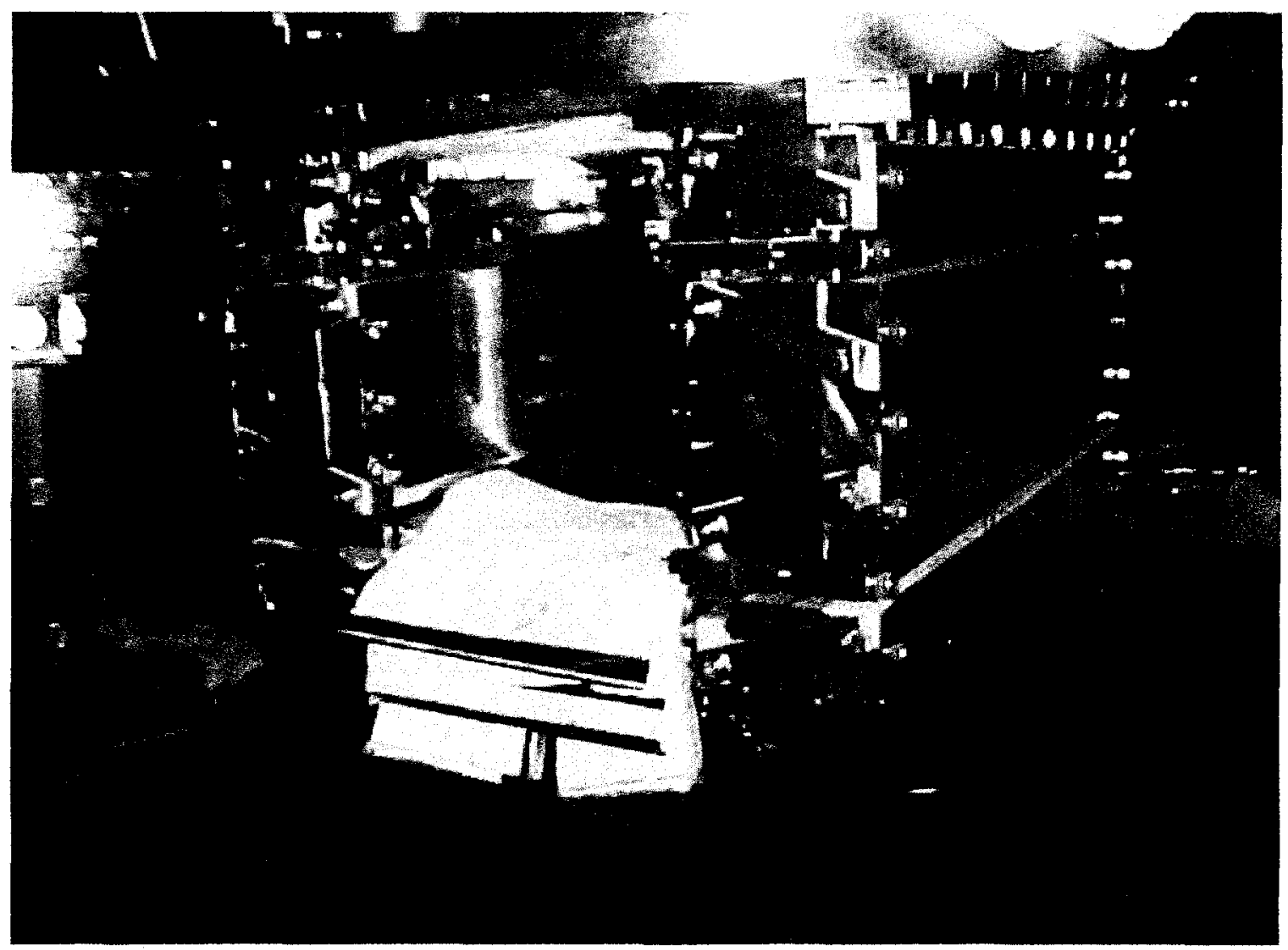

Picture 2. High emissivity tape on G-10. Prior to external insulation layers which completely enclose the cold end. Picture taken April $4^{\text {th }}$. 


\section{Operating period April 7 thru April 11}

Cool down rate was similar to the previous cycle. The platinum sensor added to stage 2 provided information about stage 2 cool down. The upper stage 1 (indicated by sensor 3 ) cooled in approximately 12 hours. The lower stage 2 reached 9 Kelvin after 24 hours and it's ultimate low temperature at $\mathrm{t}=48$ hours. The coldest temperatures measured were 7.9 $\mathrm{K}$ for sensor 1 on the cold head, and $8.0 \mathrm{~K}$ for sensor 2 on the thermal link near the cassette. I note that the display values on the ITC 503 were $0.1 \mathrm{~K}$ and $0.3 \mathrm{~K}$ higher respectively due to errors in the calibration curve.

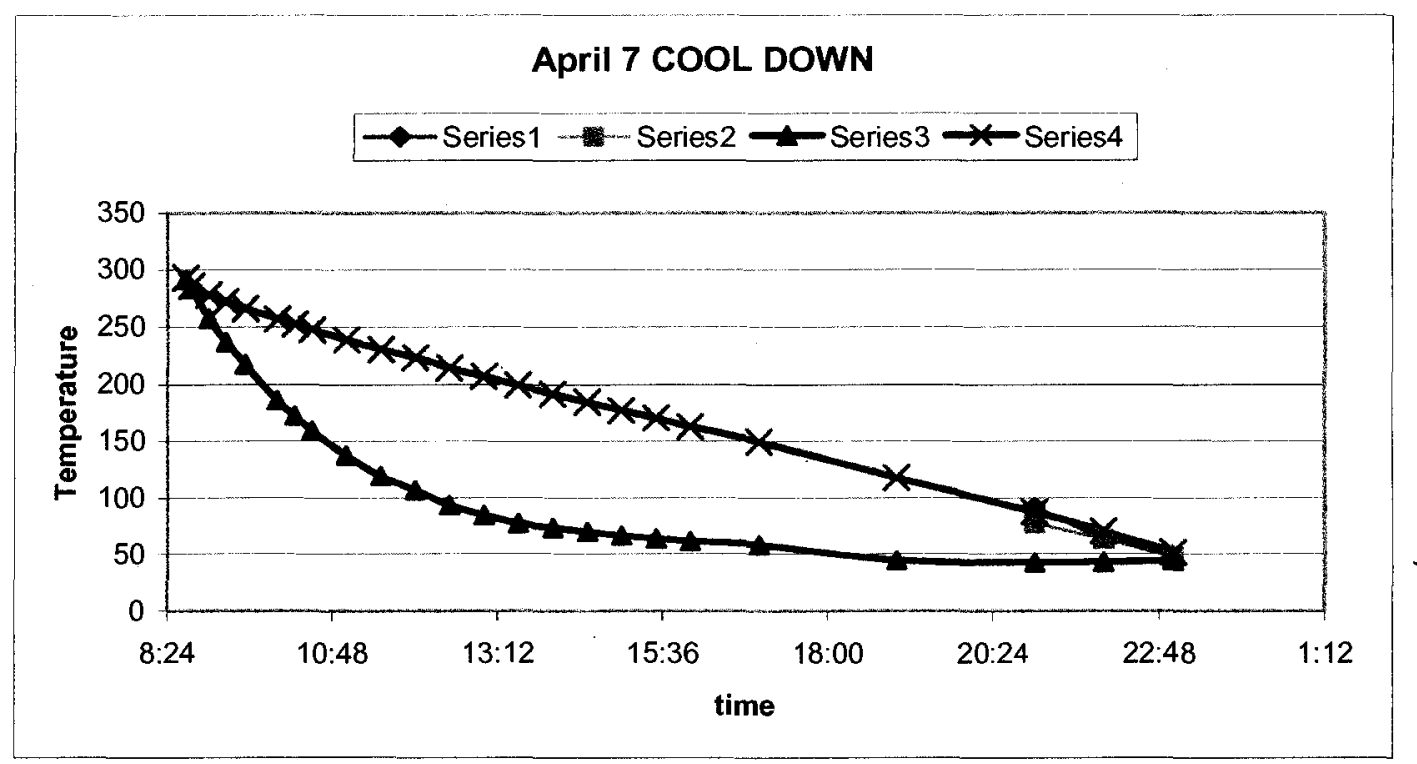

Figure 7. Cool down temperatures, $2^{\text {nd }}$ full cool down period.

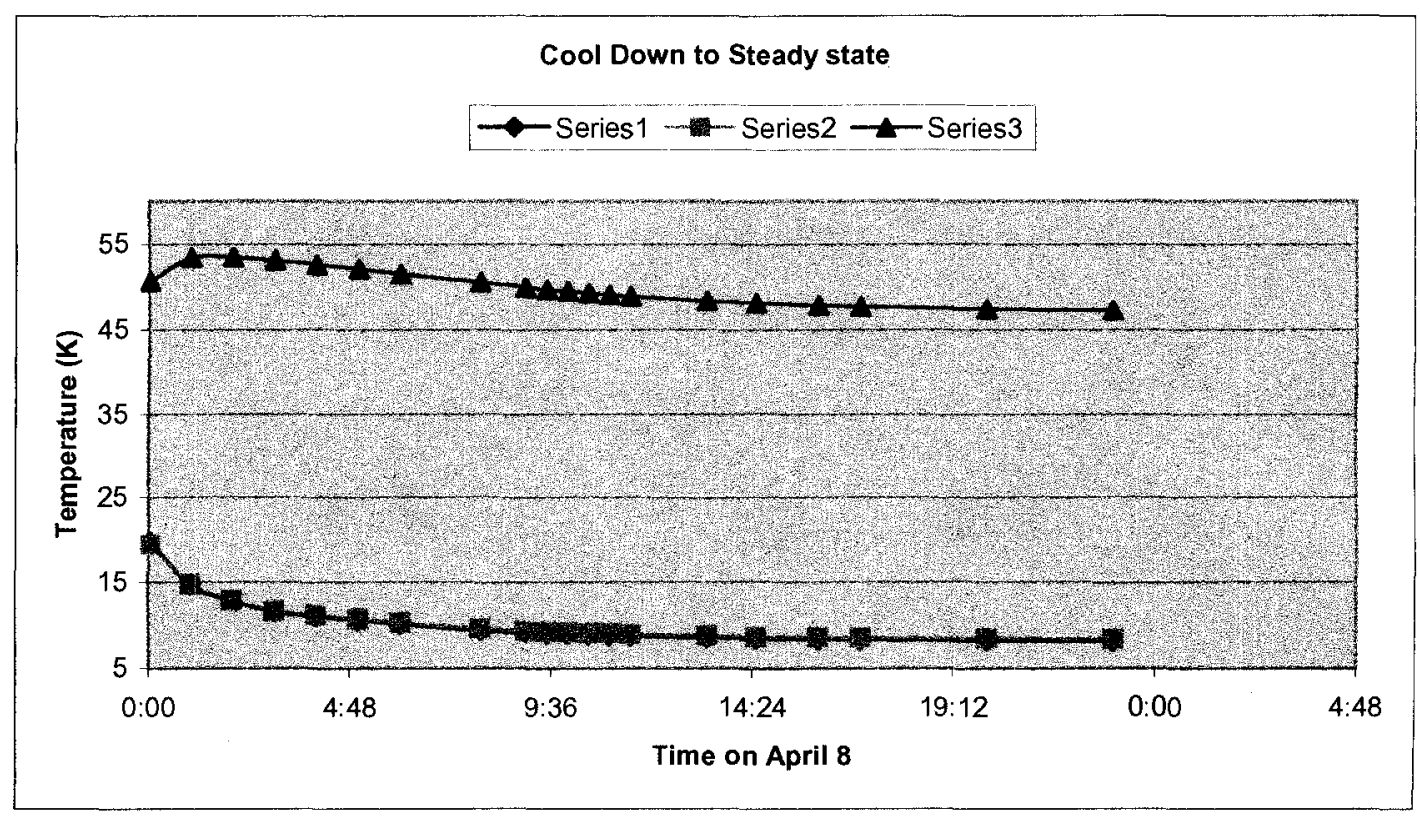

Figure 8. End of cool down, April 8. 
A heater test was performed by inputting heat to stage 2 cold head. The table and graph below show the data and a comparison to March $30^{\mathrm{th}}$. True temperatures for T1 and T2 are $0.1 \mathrm{~K}$ and $0.3 \mathrm{~K}$ lower than shown in the table.

Table 6. Temperatures during Heater power testing.

$\begin{array}{ccccccc} & \text { 30-Mar } & \text { 30-Mar } & \text { 30-Mar } & \text { 11-Apr } & \text { 11-Apr } & \text { 11-Apr } \\ \text { Heater Power } & \text { T1 } & \text { T2 } & \text { T3 } & \text { T1 } & \text { T2 } & \text { T3 } \\ 0 & 16.92 & 16.05 & 53.7 & 8.03 & 8.363 & 46.96 \\ 1 & 17.29 & 16.567 & 53.65 & 8.37 & 8.691 & \\ 2 & 17.84 & 17.236 & 53.61 & 8.67 & 8.979 & 47.48 \\ 3 & 18.74 & 18.182 & 53.61 & 9.07 & 9.396 & 47.9 \\ 4 & 19.34 & 18.792 & 53.49 & 9.62 & 9.916 & 48.34 \\ 5 & 20.33 & 19.876 & 53.27 & 10 & 10.28 & 49.36\end{array}$

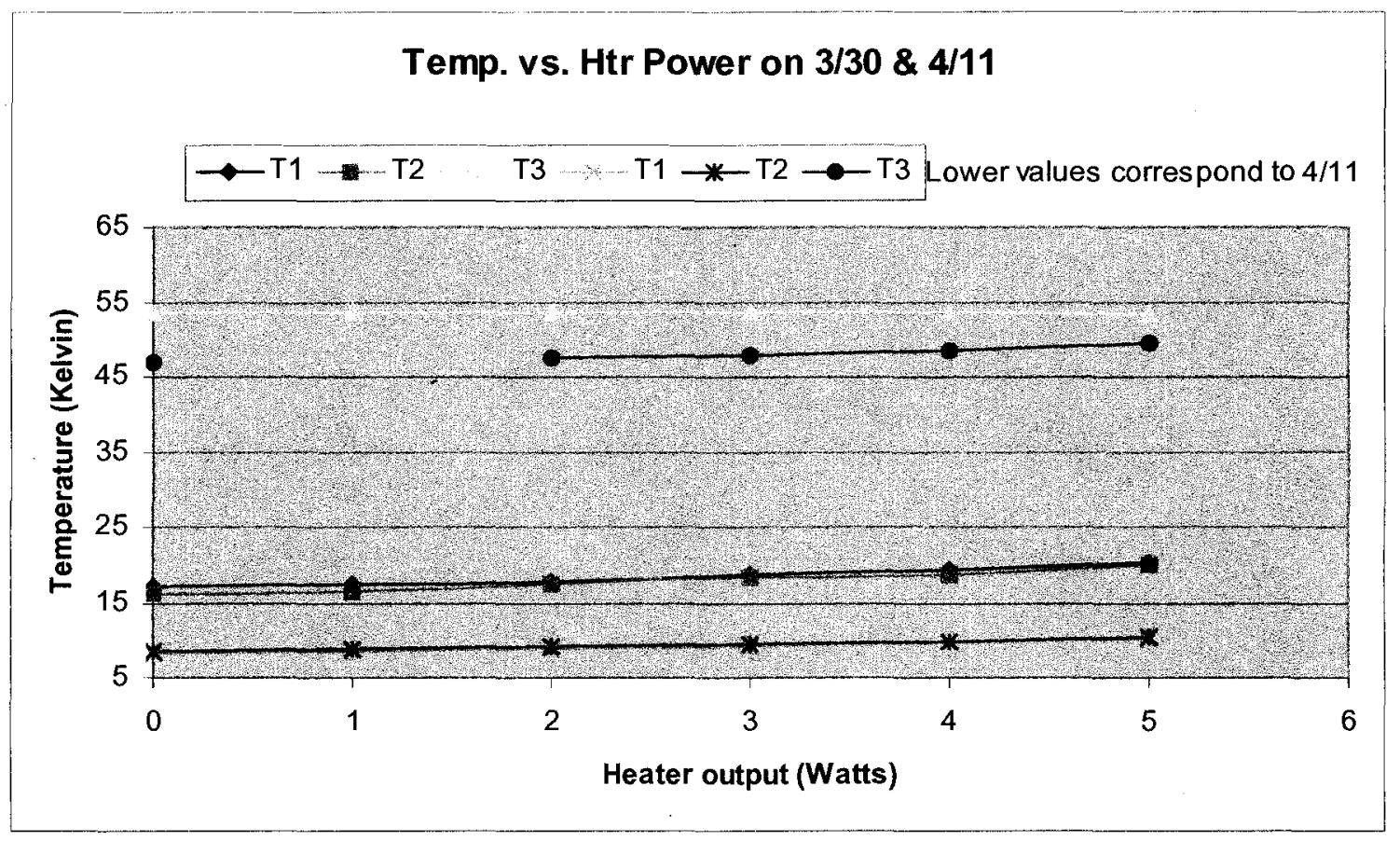

Figure 9. Temperatures during Heater power testing.

It was interesting to note that during this heater testing period, T3 the stage 1 thermal link rose in temperature as compared to the March 30 test. That behavior is consistent with the Sumitomo load map, figure 2. The heat load to the $2^{\text {nd }}$ stage during April 11 was believed to be about 10 Watts with no heater power, $15 \mathrm{~W}$ atts at full heater power. The vertical lines of the map corresponding to the $1^{\text {st }}$ stage heat load slope to the right with increasing $2^{\text {nd }}$ stage heat load in this area. During the March 30 test, the $2^{\text {nd }}$ stage heat load exceeded 15 Watts, where the $1^{\text {st }}$ stage temperature is not strongly influenced by the $2^{\text {nd }}$ stage. The 2 Kelvin rise in $2^{\text {nd }}$ stage temperature with 5 Watts is close to what the "typical" load map of figure 2 predicts. The cassette temperature was noted to rise only $0.9 \mathrm{~K}$ while the thermal link and cold head temperature rose 2 Kelvin for the $5 \mathrm{Watt}$ test. 
This was a pretty clear indication that there wasn't a good thermal connection between the stage 2 thermal link clamping bar and the cassette intercept rail. One could infer that the heat path at the very bottom of the cassette envelope was the more dominant heat path.

The cassette temperature \#111 in slot 2 was read out on the evening of April $8^{\text {th }}$. It was very disconcerting news. The cassette temperature was about 21 Kelvin. On the the following Monday, April $11^{\text {th }}$ it was about $20 \mathrm{~K}$ although the thermal link temperatures had not changed. Cassette \#105 in slot 1 was measured and found to be on average 20.7 K. A cassette heater power test was performed.

Table 7. Temperature change when running cassette heater.

$\begin{array}{cccccccc}\text { Power (Watts) } & \text { Cassette } & \text { T1 } & \text { T2 } & \text { T3 } & \text { Cass } & \text { T1 } & \text { T2 } \\ 0 & 21.10 & 8.04 & 8.37 & 47.00 & 0.00 & \text { Rise } & \text { Rise } \\ 0.345 & 22.20 & 8.15 & 8.50 & 47.00 & 1.10 & 0.11 & 0.00 \\ 1.41 & 24.68 & 8.51 & 8.87 & 47.00 & 3.58 & 0.47 & 0.50\end{array}$

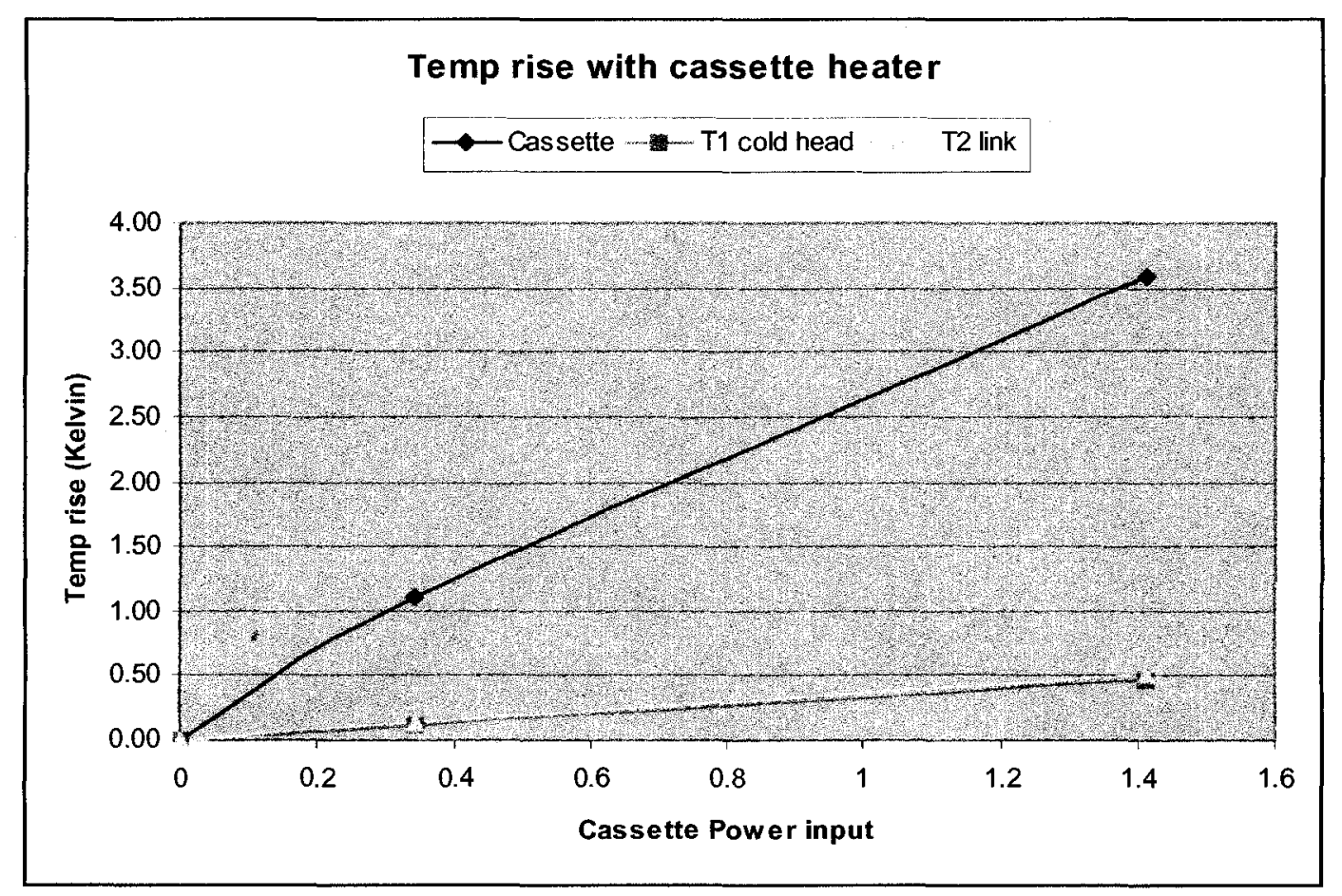

Figure 10. Temperature change when running cassette heater.

The data from the cassette heater test was very valuable. The heat load to stage 2 and the thermal resistance from cassette to the $2^{\text {nd }}$ stage can be directly calculated from this data. The heat load from cassette \#105 and the envelope was calculated to be 5.84 Watts and the thermal resistance was $2.25 \mathrm{~K} / \mathrm{W}$. This is to be compared to the design numbers of 1.3 Watts and only $0.5 \mathrm{~K} / \mathrm{W}$ thermal resistance. Total heat load for the cryo cooler would be double this number or 11.6 Watts to the second stage. 
The warm up was initiated after this testing on April 11. During warming around $20 \mathrm{~K}$, the rate of temperature rise with and without 5 Watts of cold head heater power was done. With 5 Watts the rate was $3.5 \mathrm{~K} /$ minute. Without the rate was $2.0 \mathrm{~K} /$ minute. If one assumes constant specific heat this crude test says that the stage 2 heat load at $20 \mathrm{~K}$ was about 7 Watts (without the $5 \mathrm{~W}$ heater power).

Comments: The operating point of $47 \mathrm{~K}$ for stage 1 and $7.9 \mathrm{~K}$ for stage 2 corresponds to an estimated heat load of $45 \mathrm{~W}$ atts to stage 1 and 12 Watts for stage 2 . This estimation is inferred from the Sumitomo $60 \mathrm{~Hz}$ load map. The measured thermal resistance of 2.25 $\mathrm{K} / \mathrm{W}$ is significant and can be applied to the upper stage 1 heat path as well. If one does, then the cassette temperature at the upper intercept could be estimated to be $47 \mathrm{~K}+22.5$ $\mathrm{W}^{*} 2.25 \mathrm{~K} / \mathrm{W}=98 \mathrm{~K}$. This poor intercepting of heat at stage 1 means additional heat loads to stage 2 approximately by the ratio of the temperature difference $(98 \mathrm{~K}-8 \mathrm{~K}) /(77$ $\mathrm{K}-8 \mathrm{~K})=1.3$. So design heat load values would become about $3 \mathrm{~W} * 1.3=3.9 \mathrm{~W}$. This is not enough to explain the poor performance. Upon further review of the design, the G10 stiffener panels were found to be a significant contributor of heat load. While the dimples themselves have decent thermal resistance, the solid body section is very low in thermal resistance provides good conduction among all dimples, high and low on the invar envelope. The additional heat load for this design flaw was calculated to be 21 Watts to stage 1 and 1 Watts to stage 2. This would bring the expected heat load to about $70 \mathrm{~W}$ for stage 1 and $5 \mathrm{~W}$ for stage 2 . Since the cryo cooler load map says we were taking out $45 \mathrm{~W}$ and $12 \mathrm{~W}$, evidently some of the extra heat load of stage 1 was making it to stage 2. Modifications to the cryostat were made to address the thermal contact issue and $\mathrm{G}-10$ issue.

Modifications done April 14 thru April 19: The G-10 stiffener panels between the lid and the stage 1 intercept were drilled and slotted to break the vertical conduction path. The ends of these G-10 pieces were left solid to allow the one bolt to compress the assembly. The middle (stage 1 to stage 2) G-10 panels and end pieces were physically cut into 5 slices to stop heat flow vertically. A piece of string acts as a spacer to prevent contact. The lower G-10 pieces did not need any modification as there should not be a temperature gradient in this region. The tie bars that hold the G-10 panels together were changed to run horizontally between each part, a total of 6 per cassette were added. Since the elevation of the attachment point is horizontal, and they are isolated from the envelope via the dimples, they should not add to the heat load. The changes made to the G-10 stiffeners bring the calculated heat loads back to design values. 


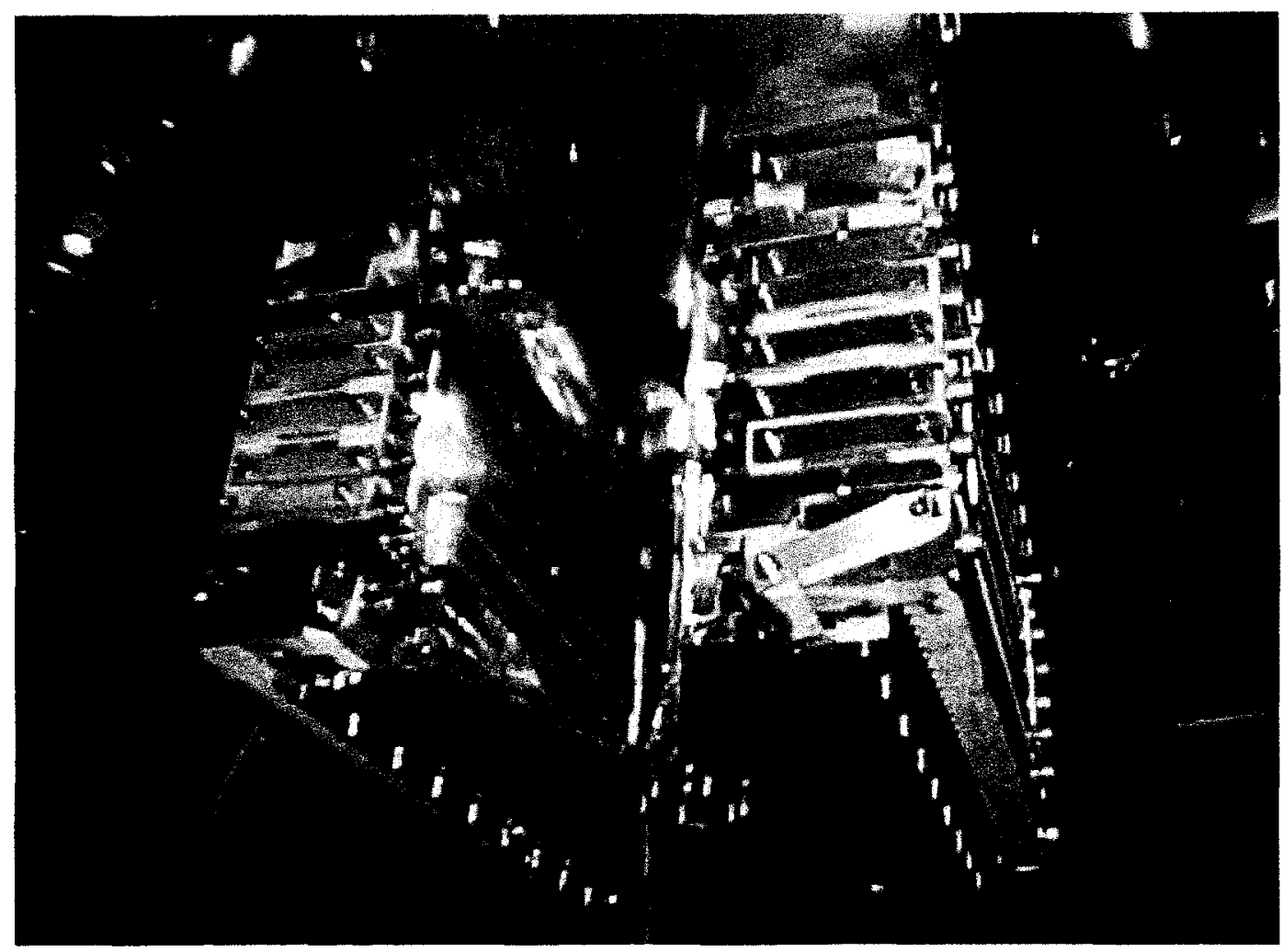

Picture 3. Modified assembly on April 18. Note segmented G-10 panels. This is prior to radiation shield and multi-layer insulation blankets.

The thermal links were the same width as the cassette envelope and were found to be only contacting the envelope strongly at the corners of the envelope. A 0.002 " shim stock was able to pass between the invar envelope and the copper link face between the corner contact proving poor/no contact. All thermal links were milled 0.010 " deep on the ends so that the contact to the envelope occurred 0.45 " away from the corner. During final assembly the interface was checked and it was found that the copper link was now contacting the invar envelope such that one could not insert a 0.002 " shim between them. A healthy layer of grease was applied at the interface. The mounting area of the thermal link to the cryo cooler stage was hand smoothed and polished to remove some tooling marks. Grease was applied liberally at this connection as well.

The stainless steel clamping bar that was designed to squeeze the link to the envelope/cassette was found to be only pushing on the copper thermal link near the edges. In fact we could easily fit a 0.020 " shim between the clamping bar and the copper link when we first inspected! See picture 4 . We milled 0.020 " deep x 1.5 " from each end so that the contact pressure would occur towards the middle. We bowed the thermal clamping bar so that it contacted the copper thermal link at the center first and then at the ends. All clamping bars were tightened such that they made good contact with the thermal link at the center and then at the ends. It was not possible to get better than three point pressure between the clamping bar and the link. 


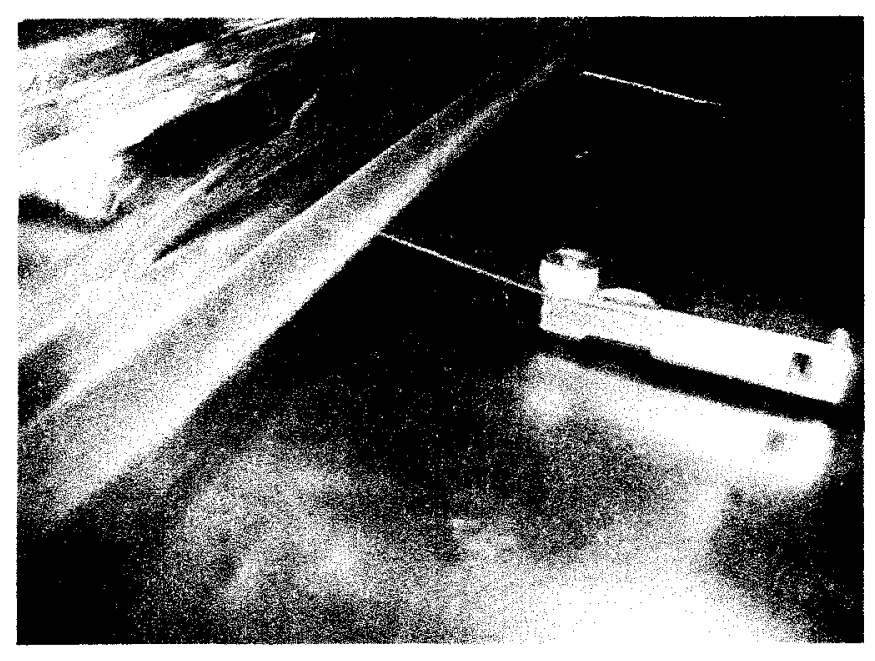

Picture 4. 0.002" gap to invar envelope and 0.020" gap to clamping bar at upper intercept, slot 1 . Note feeler gages. Picture taken April $14^{\text {th }}$ before modifications.

A hard copper radiation shield was made and attached to the first stage. It was attached at three points and should direct $290 \mathrm{~K}$ source radiation heat loads into the first stage. Multi-layer insulation was applied to the cryo cooler shaft and stage 1 thermal link (both sides) inside of the hard copper shield. Multilayer insulation was also applied outside the hard copper shield to entirely enclose the cold end assembly. The radiation shield was carefully checked to have clearances between it and all parts below the first stage. The width of the vertical section is narrower than the distance between the G-10 panels.

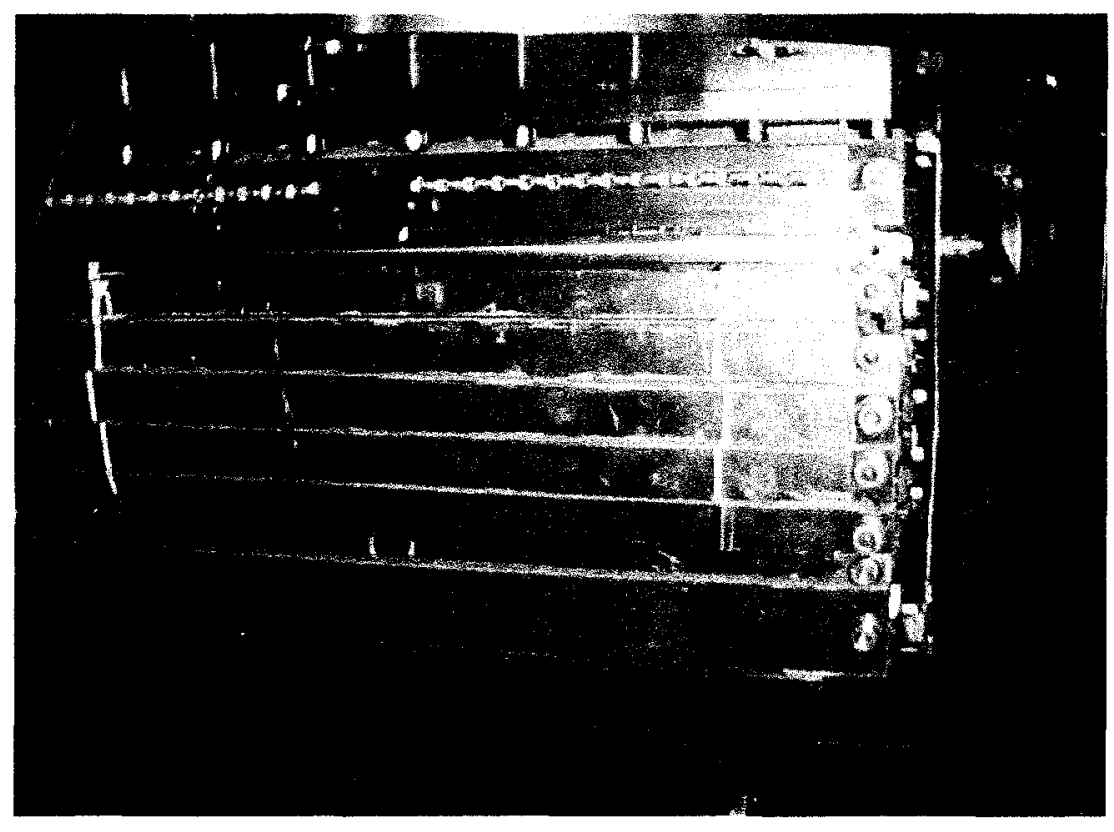

Picture 5. Cold end assembly prior to multi-layer insulation being added on inside of copper radiation bottom and around the outside of the copper radiation shield. Picture taken April $18^{\text {th }}$. 


\section{Operating period April 20 thru April 22}

Cool down rate was similar to the previous cycle. Stage 1 cooled slightly slower possibly due to the additional mass of the hard copper radiation shield.

On April 21, after 24 hours of cooling, stage 1 was at 8 Kelvin, stage 2 was 47 Kelvin both still cooling slightly. Cassette temperatures were disheartening, $19 \mathrm{~K}$ for cassette \#105 in slot 1 and $24 \mathrm{~K}$ for cassette \#111 in slot 2. Cooling continued for another day without only a few Kelvin decrease. Cassette 105 coldest temperature was 16.8 Kelvin on April 22 prior to warm up.

Temperature sensors for this operating period were as follows. Sensor 1 is a Cernox on the stage 2 cold head attachment location. Sensor 2 is a carbon resistor on the stage 2 link nearest the cassette. Sensor 3 is a silicon diode sensor on the stage 1 link nearest the cassette. Sensor 4 is a platinum sensor on the stage 1 attachment location. The calibration of the sensors in the ITC503 controller were refined during this cool down by Xiaofeng Yang. The readings were checked to be in good agreement through out the range using a decade resistor box.

Cassette heater power testing results are in Table $8 \& 9$. The zero heater power heat leak and thermal resistance from the module to the link at stage 2 was calculated. The thermal resistance values and zero heater power heat loads were high by about a factor of five. The conclusion that is drawn from this was that the upper stage 1 intercept performance is also poor and is not properly reducing the heat load to stage 2 . This is consistent with stage 1 running colder than design at 42 Kelvin ( 30 Watts from Sumitomo load map) when the expected design heat load value was 50 Watts.

Table 8. Temperature change when running cassette heater. Cassette \#111 \& 105.

$\begin{array}{ccccccccc}\begin{array}{c}\text { Power } \\ \text { (Watts) }\end{array} & \text { Cassette } & \begin{array}{c}\text { Cassette } \\ \text { Temp }\end{array} & \text { T1 } & \text { T2 } & \text { T3 } & \text { Cass } & \begin{array}{c}\text { T1 } \\ \text { Rise }\end{array} & \begin{array}{c}\text { T2 } \\ \text { Rise }\end{array} \\ 0 & \# 111 & 23.7 & 7.67 & 8.02 & 46.03 & 0.00 & 0.00 & 0.00 \\ 1.41 & \# 111 & 26.5 & 8.12 & 8.50 & 46.34 & 2.80 & 0.45 & 0.48 \\ 0 & \# 105 & 18.0 & 7.59 & 7.92 & 45.94 & 0.00 & 0.00 & 0.00 \\ 1.41 & \# 105 & 21.6 & 8.00 & 8.32 & 46.59 & 3.60 & 0.41 & 0.40\end{array}$

Table 9. Calculated thermal resistance and heat loads stage 2

\begin{tabular}{|l|l|l|l|}
\hline & 21-April & 21 -April & 11 -April - ( Ref.) \\
\hline & Slot 1- Cass\#105 & Slot 2 - Cass\#111 & Slot 1 - Cass\#111 \\
\hline Thermal Resistance & $2.3 \mathrm{Kelvin} /$ Watt & $1.7 \mathrm{Kelvin} / \mathrm{Watt}$ & $2.3 \mathrm{Kelvin} / \mathrm{Watt}$ \\
\hline Heat load (no heaters) & $4.6 \mathrm{Watts}$ & $9.3 \mathrm{Watts}$ & $5.8 \mathrm{Watts}$ \\
\hline Temperature (no htr.) & $18.0 \mathrm{~K}$ & $23.7 \mathrm{~K}$ & $21.1 \mathrm{~K}$ \\
\hline
\end{tabular}

As a last test before warm up, the heater that is attached to the stage 2 cold head was operated at 0,3 , and 5 Watts. Temperatures were recorded and are shown in Table 8. The thermal link temperature rose by 1.8 Kelvin with 5 Watts of extra heat, whereas the 
cassette temperature only rose by about half that amount, 0.8 Kelvin. This was similar to the April 11 test results. The conclusion also is the same, the thermal conduction path at stage 2 is probably dominated by the bottom strap rather than the side clamping bars and the thermal connection was poor.

The vacuum pressure during this operating period was monitored with a cold cathode gauge. The pressure dropped from 3.7E-4 Torr warm to 8.0E-7 Torr at cold temperatures. These vacuum pressures are excellent for cryogenic operation.

Table 10. Temperatures during Heater power testing.

$\begin{array}{cccccc} & \text { 22-Apr } & \text { 22-Apr } & \text { 22-Apr } & \text { 22-Apr } & \text { 22-Apr } \\ \text { Heater Power } & \text { T1 } & \text { T2 } & \text { T3 } & \text { T4 } & \text { Cassette } \\ 0 & 7.20 & 7.47 & 44.38 & 41.28 & 16.8 \\ 3 & 8.14 & 8.36 & 46.66 & 43.56 & 17.1 \\ 5 & 8.97 & 9.14 & 47.63 & 44.54 & 17.6\end{array}$

Comments: The overall heat loads for this operating period were reduced from the previous iteration. Segmenting the G- 10 body panels and the addition of the hard radiation shield reduced overall heat load values for stage $1 \&$ stage 2 from $45 \mathrm{~W} \& 10 \mathrm{~W}$ to about $38 \mathrm{~W} \& 7 \mathrm{~W}$. There was no apparent improvement in the thermal connection at the clamping bars. This was the focus of the next modification.

Modifications done April 25 thru April 27: The thermal connection between the thermal link and the envelope in the vacuum space was the focus of testing and improvement. We found that the Apiezon "N" cryogenic grease got hard and brittle at LN2 temperatures. This is okay for bonds between like materials like copper to copper. This was not good for a bond between the copper link that shrinks due to thermal contraction and the invar that shrinks very little. Two copper pieces bonded with the grease remained solidly bonded when cooled and submerged in a $78 \mathrm{~K}$ liquid nitrogen bath. A copper piece bonded to invar with grease separated by itself when subjected to this test.

Testing was done using the spare invar envelope with the thermal clamp attached. The assembly was checked at room temperature for a tight clearance of less than 0.002 " along its length. Backlighting the interface showed about $50 \%$ of the length was light tight. The assembly was then dunked in an open LN2 bath and the clearance of the link to the envelope checked. What was found was that the invar envelope developed a wavy buckled profile and pulled away from the copper link such that there were significant gaps along the interface. This was very instructive. It is believed that the copper link locked in the invar at the outer edges of the width fairly well. When the copper dimension shrank, it put the main span of the thin invar envelope into compression with the extra material making the wavy pattern. No grease was used during the test, but it is clear that had grease been in the gap, it would have just cracked and opened up.

The improvement made during this iteration was to solder indium (98\% In, $2 \% \mathrm{Ag})$ to the mating surfaces of the copper thermal link and the invar envelope. Indalloy flux \#3 was 
used to adhere the indium to the invar. A Kester flux was used on the copper pieces. The coating thicknesses are estimated to be about 0.008 inches thick. At assembly, a single piece of indium wire 0.065 " diameter by 14 " long was squeezed in the joint. Testing in the open LN2 bath showed that the joint remained closed and solid. Compression of the test wire was measured to give about 1.75 square inches of contact area. Picture 6 shows the compression of the wire after our test. The indium wire melded or stuck to the envelope in places indicating good bonding. Thermal resistance of a solid indium path of these dimensions is very small, only $0.02 \mathrm{~K} / \mathrm{W}$ at stage 1 and similarly small at stage 2 .

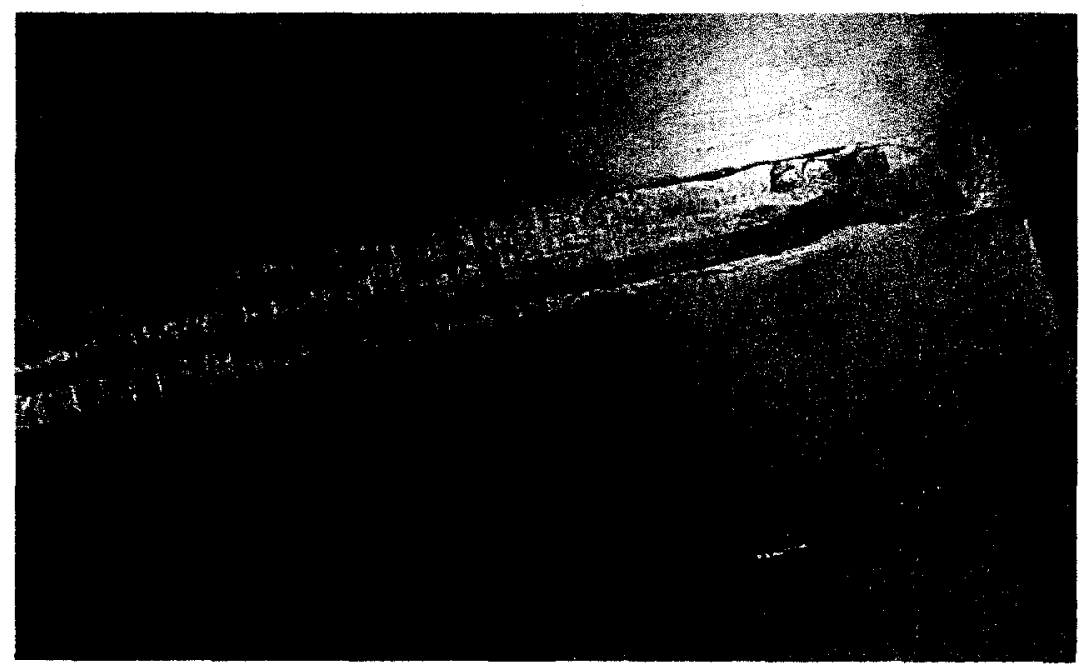

Picture 6. Compressed indium wire on test envelope after LN2 cold test.

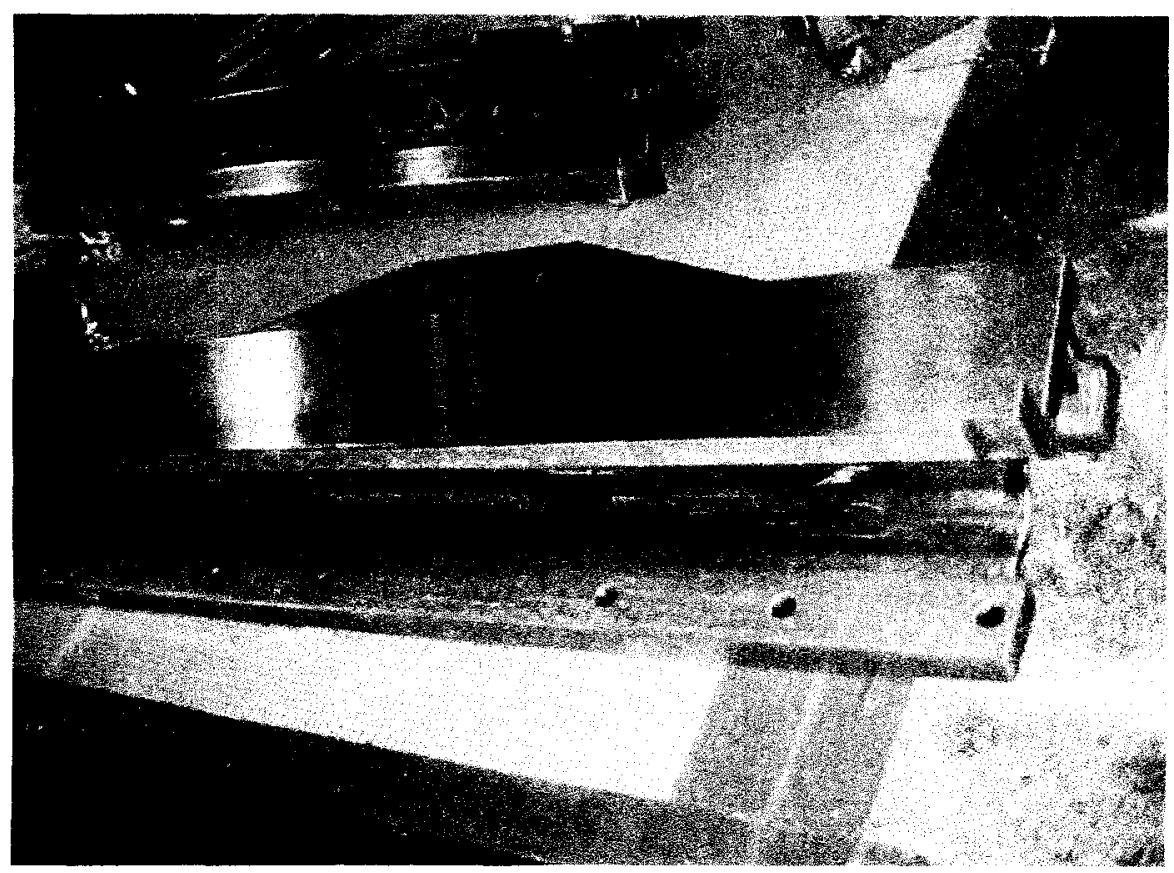

Picture 7. Indium coated thermal links. 
During the soldering on the envelope, both cassettes were removed from the cryostat. They slid in and out very easily (with everything removed from the exterior of the envelope. No damage or evidence of hard service was seen on the cassettes.

Another change made was to add a copper braid, 0.017 inches thick $x 0.220$ inches wide under the outboard clamping bar of the stage 1 intercept. The braid makes a thermal connection between the envelope surface opposite the cryo cooler with the thermal link The copper braid wraps around the envelope and then is sandwiched between the backside of the copper thermal link and the inboard stainless steel clamping bar. The path has a calculated thermal resistance of about $15 \mathrm{~K} / \mathrm{W}$. The braid has some compressibility and kept the invar envelope from developing the wavy pattern during LN2 bath tests.

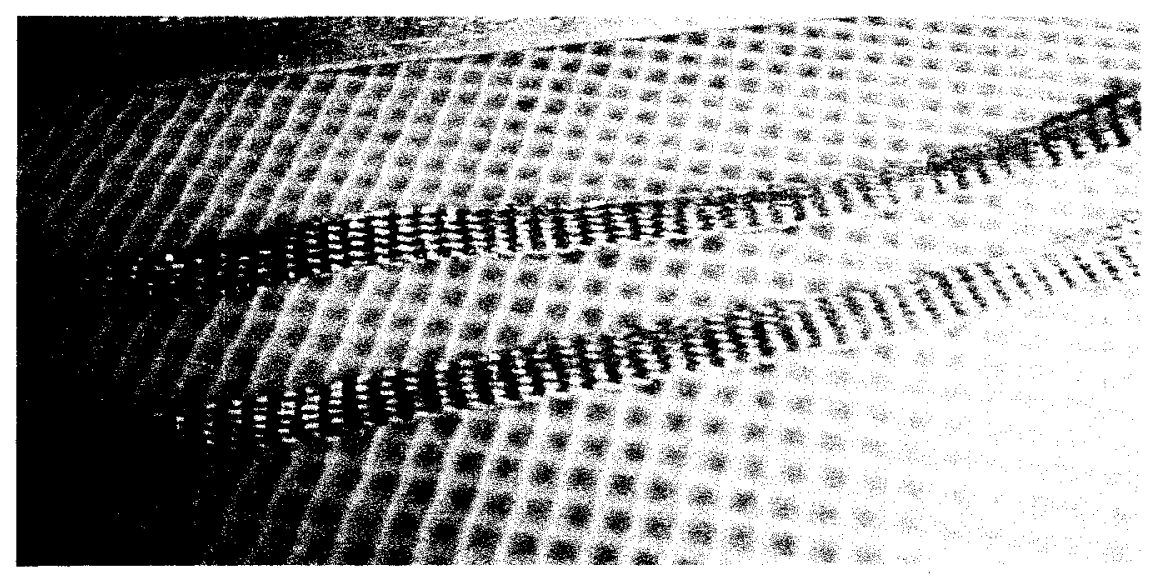

Picture 8. Flexible braid, Pro-Wick solder removal braid, 0.210 " width. 
Page 20

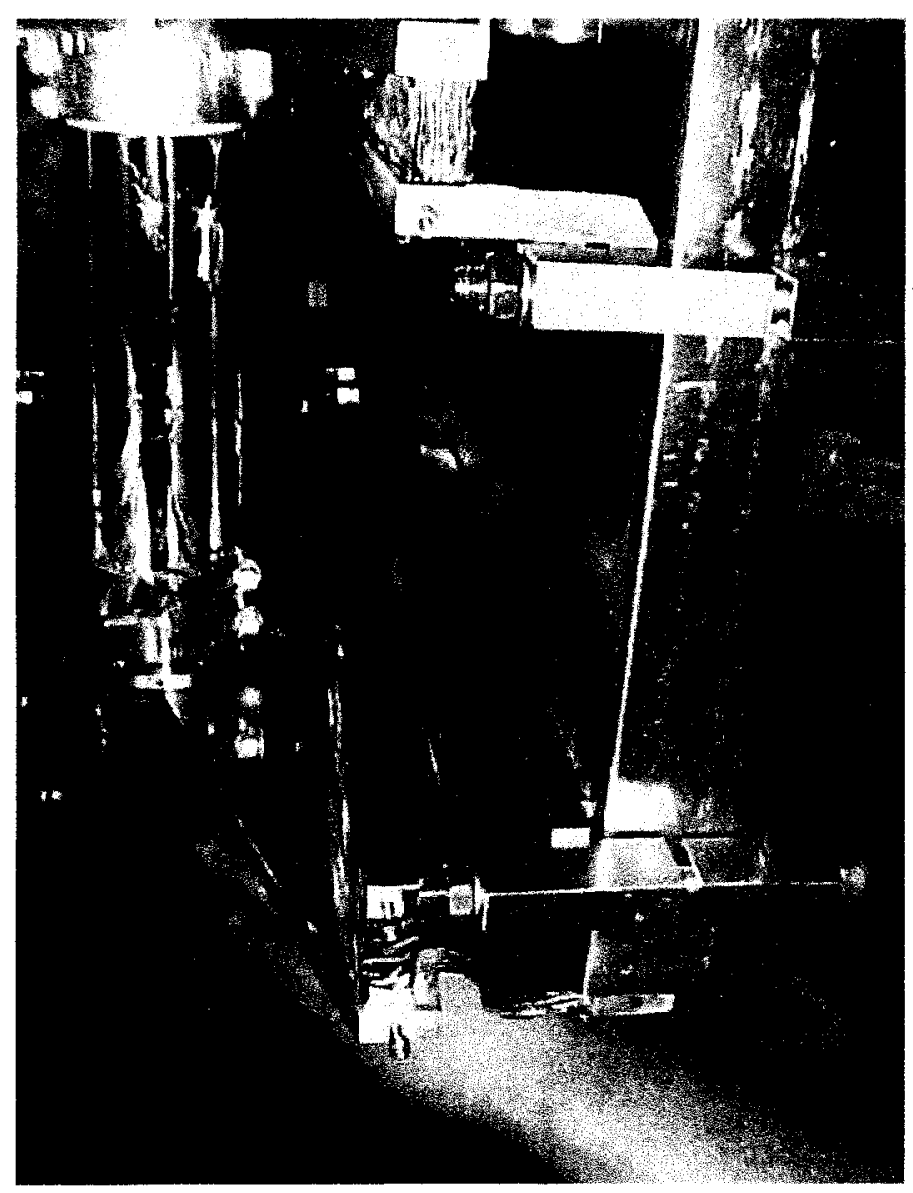

Picture 9. Assembly with indium wire at interface. Taken April 27, 2005.

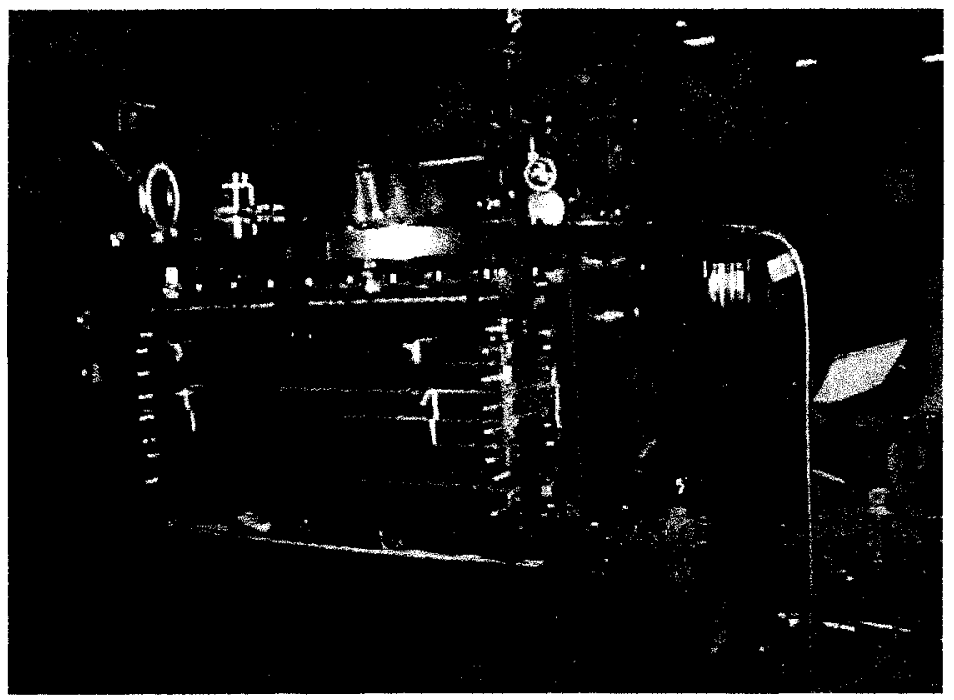

Picture 10. Assembly ready for more super insulation, April 27, 2005. 


\section{Operating period April 28 thru May 6th (ongoing)}

Cool down started on April $28^{\text {th }} 8: 30$ am. The cool down rate was a little different than previous cycles in an encouraging way. The upper stage cooled at a slower rate than previous operating periods. The temperature difference across the thermal link, T3 minus T4 was larger, around 19 Kelvin during the cooling period $294 \mathrm{~K}$ to $150 \mathrm{~K}$ whereas the previous cool down it was around 14 Kelvin. A larger temperature gradient across the thermal link means that more heat is being transferred through it. The lower stage 1 cooled slightly faster indicating that the steady state heat load to that stage was decreased from previous operations.

The cool down of the thermal mass is significant compared to steady state heat loads for the first 12 hours. Stage 1 and stage 2 equally share a total thermal mass of 4.6 megajoules. About half of the thermal mass is due to the $25 \mathrm{~kg}$ mass (total for both stages) of the copper thermal links. The average cooling power during the cool down can be estimated to be $4.6 \mathrm{MJ} / 24 \mathrm{hrs} * 1 \mathrm{hr} / 3600 \mathrm{~s}+55 \mathrm{~W}$ steady state heat load $=108 \mathrm{Watts}$. That is consistent with cryo cooler load map, with a stage 1 upper capacity of 80 Watts and stage 2 upper capacity of 20 Watts.

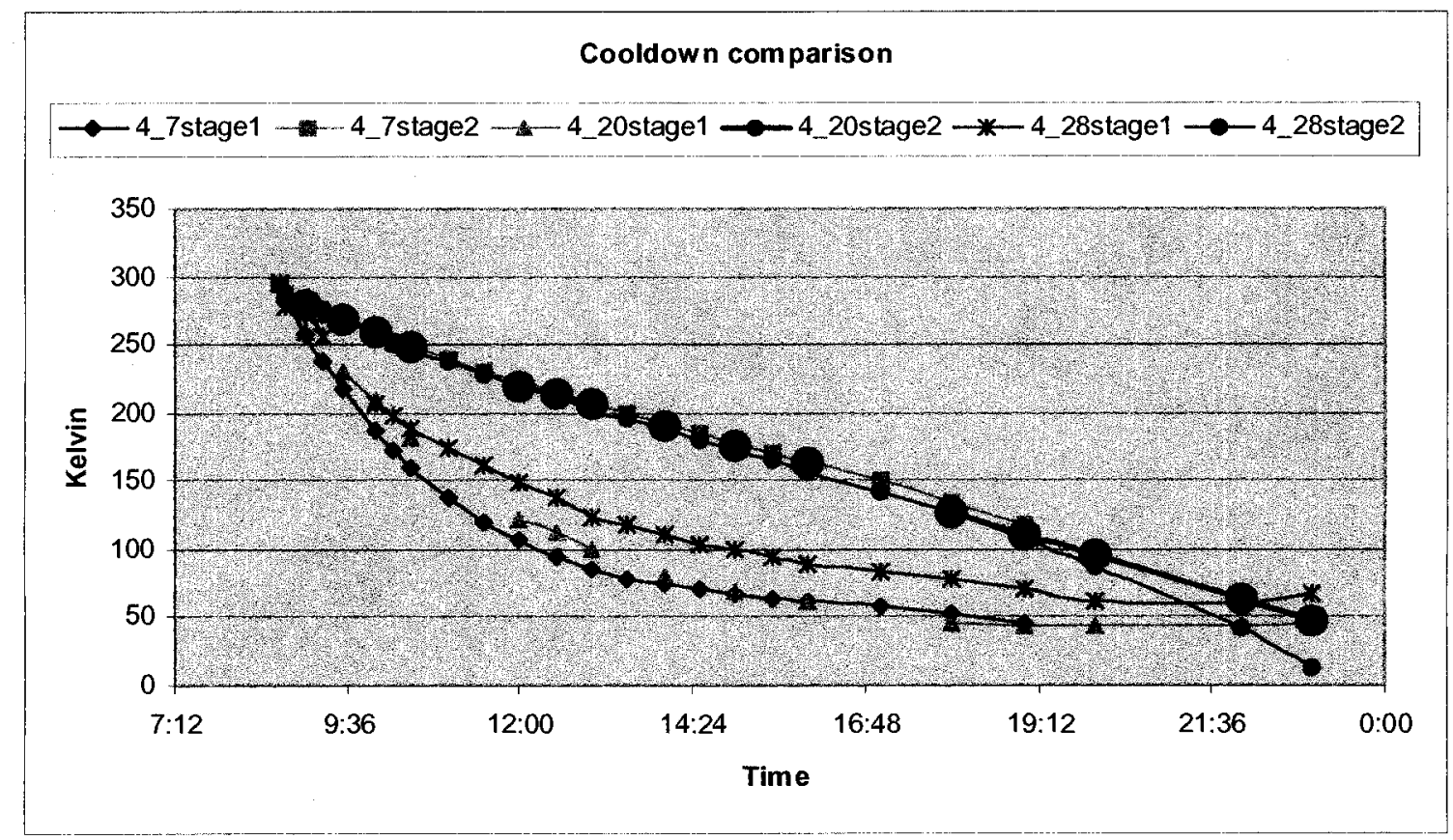

Figure 11. Cool down comparison. On April $28^{\text {th }}$, the system is working better.

The cassette \#111 module temperature was monitored during this cool down. Resolution of the carbon resistors in the cassette is poor in the upper temperature range. We were able to get readings below 160 Kelvin and were very encouraged to see that the cassette temperature was always within about 5 Kelvin of T2, the stage 2 thermal link temperature. This was another preliminary indication that the thermal connection between the link and the envelope/cassette was good. 
After 24 hours the majority of cooling had taken place. The cassette was found to have reached it's required operational temperature of 9 Kelvin. Success was communicated among the collaboration. As you can see from the table below, the cassettes continued to cool. Cassette \#105 steady state temperature without external heaters is 7.5 Kelvin and cassette \#111 is less than $7.1 \mathrm{~K}$, probably around $6.8 \mathrm{Kelvin}$.

Table 11. Temperatures during cool down and steady state

\begin{tabular}{|c|c|c|c|c|c|c|c|}
\hline Date\& Time & $\begin{array}{c}\text { time } \\
\text { (hrs) }\end{array}$ & T1 & T2 & T3 & T4 & $\begin{array}{c}\text { Slot 1 } \\
\# 105\end{array}$ & $\begin{array}{c}\text { Slot 2 } \\
\# 111\end{array}$ \\
\hline Apr-28, 8:30 & 0 & 294.5 & 294.8 & 294.8 & 294.7 & 294 & 294 \\
\hline Apr-28, 20:00 & 11.5 & 86.2 & 91.0 & 61.8 & 52.8 & - & 84 \\
\hline Apr-29, 8:00 & 23.5 & 6.41 & 6.62 & 57.45 & 50.45 & - & 8.63 \\
\hline Apr-29, 14:00 & 29.5 & 5.44 & 5.59 & 54.34 & 47.60 & 7.85 & 7.15 \\
\hline Apr-29, 21:00 & 36.5 & 5.34 & 5.47 & 54.08 & 47.38 & 7.60 & - \\
\hline Apr-30, 9:00 & 48.5 & 5.27 & 5.40 & 53.94 & 47.28 & 7.52 & - \\
\hline May-1,9:00 & 72.5 & 5.27 & 5.40 & 53.97 & 47.30 & 7.44 & - \\
\hline
\end{tabular}

The cryostat met the expected design values very well. See table below.

Table 12. Actual Performance versus Design.

\begin{tabular}{|l|c|c|}
\hline Operating period & $\begin{array}{c}\# 4 \\
\text { April } 28\end{array}$ & $\begin{array}{c}\text { Design } \\
\text { Values }\end{array}$ \\
\hline Stage 1 lowest & $47 \mathrm{~K}$ & 45 Kelvin \\
\hline Stage 1 heat load & $55 \mathrm{~W}$ & 50 Watts \\
\hline Stage 2 lowest & $5.3 \mathrm{~K}$ & 5.5 Kelvin \\
\hline Stage 2 heat load & $\mathbf{3}$ to $4 \mathrm{~W}$ & 3 Watts \\
\hline Slot 1, Cass\#105 & $7.5 \mathrm{~K}$ & 8 Kelvin \\
\hline Slot 2, Cass\#111 & $7.1 \mathrm{~K}$ & 8 Kelvin \\
\hline
\end{tabular}

Cassette heater power tests were done. 1.5 Watts of power was inputted into the cassette. 0.1 Watts is dissipated in the flex circuit, 1.4 Watts at the cold end isotherm. The temperature difference between the cassette isotherm and stage 2 thermal link, T2 were recorded. The calculated results are shown in the table below.

Table 13. Calculated thermal resistance and heat loads stage 2

\begin{tabular}{|l|l|l|l|l|}
\hline & $29-$ April & $29-$ April & 21 -April - (Ref) & 21-April - (Ref) \\
\hline & $\begin{array}{l}\text { Slot 1- } \\
\text { Cass\#105 }\end{array}$ & $\begin{array}{l}\text { Slot } 2- \\
\text { Cass\#111 }\end{array}$ & $\begin{array}{l}\text { Slot 1- } \\
\text { Cass\#105 }\end{array}$ & $\begin{array}{l}\text { Slot } 2- \\
\text { Cass\#111 }\end{array}$ \\
\hline Thermal Resistance & $2.3 \mathrm{~K} / \mathrm{W}$ & $1.7 \mathrm{~K} / \mathrm{W}$ & $2.3 \mathrm{Kelvin} / \mathrm{Watt}$ & $1.7 \mathrm{Kelvin} / \mathrm{Watt}$ \\
\hline Heat load (no heaters) & $1.0 \mathrm{Watts}$ & $0.9 \mathrm{Watts}$ & $4.6 \mathrm{Watts}$ & $9.3 \mathrm{Watts}$ \\
\hline Temperature (no htr.) & $7.85 \mathrm{~K}$ & $7.15 \mathrm{~K}$ & $18.0 \mathrm{~K}$ & $23.7 \mathrm{~K}$ \\
\hline
\end{tabular}

It is interesting to note that the calculated thermal resistance value from the module to the thermal link came out to be exactly the same value as measured during the previous 
iteration. It is also interesting that the value falls in the range of all seventeen past measurements of this thermal resistance value. This includes all measurements I have made dating back to 1997 using other D-Zero cryostats (the four cassette cryostat and the full cryostat) and cassettes. The measured value has always been between $1.67 \mathrm{~K} / \mathrm{W}$ (minimum value) and $2.35 \mathrm{~K} / \mathrm{W}$ (maximum) with a most common value of around 2.2 $\mathrm{K} / \mathrm{W}$. One could speculate that cassette geometry or the gas helium heat transfer occurring inside the cassette dominates the thermal resistance. For this speculation to hold for the April 11 and April 21 measurements, one would need to assume that the bottom thermal strap (bolted bar with thermal grease) compensated for the poor connection at the stage 2 thermal clamp.

The cassette heaters were turned off and the temperature control heater on stage 2 was turned on using the ITC503 controller. It was put into automatic control with a cold head temperature set point of $7.35 \mathrm{~K}$. The controller worked very well giving a stable temperature of better than $0.10 \mathrm{~K}$. A heater output of 13.1 to 13.2 volts $=5$ Watts $+/-0.1$ Watts regulated this temperature. Cassette 105 ran at 9.2 Kelvin and cassette 111 ran at $8.7 \mathrm{~K}$ for this condition. This value was exactly the expected value!

Table 14. Temperature control test.

$\begin{array}{ccccccc}\text { Heater } & \text { 29-Apr } & \text { 29-Apr } & \text { 29-Apr } & \text { 29-Apr } & \text { 29-Apr } & \text { 29-Apr } \\ \text { Power } & \text { T1 } & \text { T2 } & \text { T3 } & \text { T4 } & \text { Cass 105 Cass 111 } \\ 0 & 5.47 & 5.60 & 54.36 & 47.65 & 7.85 & 7.15 \\ 5 & 7.35 & 7.48 & 57.91 & 51.08 & 9.2 & 8.7\end{array}$

The cryostat has been running for 1 week without noticeable change in temperature or performance. The disparity in cassette temperature can be taken out by running the cassette heater of the colder cassette. Thermal cycle tests still need to be done to check that the intercept thermal clamp connection is stable.

\section{Future Recommendation}

The thermal clamp connection works, but is not a robust dependable design. Any future cryo cooler cryostats should include an improvement in this area that incorporate a bolted connection and/or interfaces that tighten in contact pressure when cold.

\section{Acknowledgements}

James E. Fagan (team leader), Robert Kubinski, Rolando Flores, and Chris Tolian were the technician staff that assembled the cryostat and helped make the modifications necessary during the assembly and commissioning of the cryostat. Several hurdles were overcome through their ingenuity and hard work. Koji Yoshimura (KEK) and Shigeru Ishimoto (KEK) took care of the detail part fabrications by the Jecctorisha cryogenic company in Japan. Jack Mateski (FNAL) was my designer drafter who made the fabrication drawings. Alan Bross (FNAL), Koji, Shigeru, Mike Sarychev (FNAL), and Richard Schmitt (FNAL) gave valuable advice and assistance during the commissioning period. Alan, Shigeru, Koji, and other members of the M.I.C.E. collaboration also gave insightful commentary during design and status meetings. 